\title{
Variability of Multisite Decadal Running Means Arising from Year-To-Year Fluctuations $\mathscr{O}$
}

\author{
Xiaogu Zheng a and CARsten S. Frederiksen ${ }^{\mathrm{b}, \mathrm{c}}$ \\ ${ }^{a}$ CAS Key Laboratory of Regional Climate-Environment for Temperate East Asia, Institute of Atmospheric Physics Chinese \\ Academy of Sciences, Beijing, China \\ ${ }^{\mathrm{b}}$ CSIRO Oceans and Atmosphere, Aspendale, Victoria, Australia \\ ${ }^{\mathrm{c}}$ The Bureau of Meteorology, Melbourne, Victoria, Australia
}

(Manuscript received 2 June 2020, in final form 21 October 2020)

\begin{abstract}
Decadal mean variables are frequently used to characterize decadal climate variabilities. Decadal means are often calculated using yearly data, which can represent variability at time scales from annual to centennial. Residuals from interannual fluctuations may contribute to the variability in decadal time series. Such variability is more difficult to be predicted at the long range. Removing it from the decadal variability means that the remaining variability is more likely to arise from slowly varying multidecadal or longer time scale external forcing and internal climate dynamics, which are more likely to be predicted. Here, a new approach is proposed to understand the uncertainty, potential predictability, and drivers of decadal mean variables. The covariance matrix of multivariate decadal running means is decomposed into unpredictable fast decadal variability and the potentially predictable slow decadal variability. EOF analysis is then applied to the decomposed matrices to find the dominant modes, which may be related to the drivers of the two types of variabilities in the multivariate decadal means. The methodology has been applied to 140-yr datasets of North Pacific sea surface temperature and the Northern Hemisphere 1000-hPa geopotential height. For sea surface temperature, the Pacific decadal oscillation is the major driver of the fast decadal variability, while the radiative forcing and the Atlantic multidecadal oscillation are major drivers of the slow decadal variability. For the 1000-hPa geopotential height, fast decadal variability is associated with the northern annular mode, the east Atlantic mode, and the Pacific decadal oscillation. Slow decadal variability is associated with the northern annular mode and the Atlantic multidecadal oscillation.
\end{abstract}

KEYWORDS: Decadal variability; Interannual variability; Interdecadal variability; Multidecadal variability; Pacific decadal oscillation; Trends

\section{Introduction}

Decadal means are a popular statistic for decadal climate variability (e.g., Watanabe et al. 2014; Allen et al. 2013; Knight 2009; Watterson and Whetton 2011). Climate scenarios, such as in the Intergovernmental Panel on Climate Change assessment reports, also use decadal mean variables as the baseline of future climate. Therefore, it is crucial to better understand the uncertainty, predictability, and drivers of the decadal mean variables.

In decadal climate variability studies, it is important to bear in mind the null hypothesis that any low-pass filtered time series will exhibit decadal climate variability, but it need not be physically meaningful (i.e., it may not be distinguishable from a random process) (Deser and Phillips 2017). A decadal mean of a climate variable (i.e., the sample mean of the yearly data within the decade) could be thought of as consisting of two components. The first is just the decadal population mean. The second is the decadal mean of the departures of yearly data from the decadal population mean (e.g., Boer 2004;

Supplemental information related to this paper is available at the Journals Online website: https://doi.org/10.1175/JCLI-D20-0414.s1.

Corresponding author: Carsten Frederiksen, Carsten.Frederiksen@ bom.gov.au
Frederiksen et al. 2016). The first is more likely to be driven by physical processes with slow decadal variability and is referred to as the slow component, while the second is more likely arising from random year-to-year fluctuations and is referred to as the fast component. This implies that decadal means may not be only driven by physical processes with decadal or longer variability; they may also be driven by physical processes with significant year-to-year fluctuations (e.g., Boer 2004; Frederiksen et al. 2016). Although the decadal mean filter will not numerically separate the two components of a decadal mean, some previous studies indicate that the covariance between the fast components of two decadal mean series can be estimated using yearly data. With such an estimation, the covariance between the two slow components of decadal means can be estimated by subtracting the covariance between the fast components from the covariance between the two sets of decadal means (e.g., Frederiksen et al. 2016).

In previous studies, the variance of a fast component was estimated under the assumption that the annual population means of a yearly climate variable is constant within a decade (e.g., Boer 2004; Frederiksen et al. 2016). However, this may not be true in practice. For example, if yearly variability is strongly forced by global warming, linear trends exist not only in multidecadal time series, but also within most decadal intervals. Even for yearly data embedded within multidecadal variability, such as the Atlantic multidecadal oscillation (AMO) index (Trenberth and Shea 2006), there can be upward or downward trends within many decadal intervals. In 
the present study, linear trends within decadal intervals are considered in the estimation of decadal variability arising from fast variability. Although the existence of linear trends within decadal intervals does not change the decadal means, because they can be completely removed by the decadal mean filter, it is demonstrated in this paper that ignoring the linear trends within decadal intervals can cause an overestimation of the decadal variability of the fast component. As a result, in this paper an unbiased estimation of the decadal variance of the fast component is proposed based on a second-order difference operator, which it is shown can allow for the presence of linear trends within decadal intervals.

To achieve a robust and stable result, using existing diagnostic approaches (e.g., Boer 2004, 2009; Frederiksen et al. 2016), yearly data over many tens of decades are required. Otherwise, the results may be sensitive to the initial starting years. This may not be a problem for model data generated in multicentennial simulations (e.g., Frederiksen et al. 2016). It could be a problem for reanalysis data and observations, because instrumental records only exist for at most 150 years. Up until now, the analysis has only been applied to simulated data (e.g., Boer 2004, 2009; Frederiksen et al. 2016, 2017; Lou et al. 2017; Ying et al. 2018). However, such studies are subject to model errors, which may lead to, for example, the variability of the fast or intradecadal components being too large or too small. In the present study, decadal running means are used to remove the sensitivity for shorter time series.

To illustrate the methodology, the analysis has been applied to 140 years of the Extended Reconstructed Sea Surface Temperature dataset version 5 (ERSSTv5) (Huang et al. 2017) in the North Pacific. As a second atmospheric example, we have applied the methodology to the Twentieth Century Reanalysis (20CR) version 3 (Compo et al. 2011) 1000-hPa geopotential height dataset. Our purpose is to illustrate that the proposed methodology does indeed separate the total variance of decadal means into the fast and the slow components. We also show that there is additional information possible when the decomposition into slow and fast components is applied. In a future study, the methodology will be applied to a more in-depth study of decadal variability in global SST.

The outline of this paper is as follows. The methodology is described in section 2, and its application to the ERSSTv5 data is described in section 3 and to 20CR data in section 4. Our conclusions are given in section 5 .

\section{Methodology}

\section{a. Statistical model for decadal means}

Allowing for the possibility of a linear trend within a decade, a meteorological variable $x_{d, y}$, for a year $y(=1, \ldots, 10)$ within a decade $d$, can be conceptualized as

$$
x_{d, y}=\mu_{d}+\beta_{d}(y-5.5)+\varepsilon_{d, y},
$$

where $\mu_{d}$ is the population mean of the decadal average, $\beta_{d}$ is the linear trend within the decade, and $\varepsilon_{d, y}$ is the residual.

Since annual means of many meteorological variables are Gaussian distributed and can be approximated by a Markov process (Leith 1973; Trenberth 1984), it is assumed that $\left\{\varepsilon_{d, y}\right\}$ is an autoregressive process of order $1[\operatorname{AR}(1)]$. That is,

$$
\varepsilon_{d, y+1}=\alpha \varepsilon_{d, y}+\eta_{d, y+1},
$$

where $\alpha$ is the yearly autocorrelation coefficient of the residuals, and $\left\{\eta_{d, y}\right\}$ are white noise. The value of $\alpha$ can be estimated by minimizing the sum of the -2-ln-likelihood functions of the random variables $\left\{\nabla^{2} \varepsilon_{d, i+y}, y=3, \ldots, 10\right\}$ given the outcome $\left\{\nabla^{2} x_{d, i+y}, y=3, \ldots, 10\right\}$ [Eq. (A6) of appendix A with $i=0$ ] over $d=1, \ldots, D$, where $\nabla$ is the first-order difference operator

$$
\nabla x_{d, y}=x_{d, y}-x_{d, y-1},
$$

and $\nabla^{2}$ is the second-order difference operator

$$
\begin{aligned}
\nabla^{2} x_{d, y} & =\nabla\left(\nabla x_{d, y}\right) \\
& =\nabla\left(x_{d, y}-x_{d, y-1}\right)=x_{d, y}-2 x_{d, y-1}+x_{d, y-2} .
\end{aligned}
$$

The decadal mean of $x_{d, y}$ is then represented by

$$
x_{d, o}=\mu_{d}+\varepsilon_{d, o},
$$

where $x_{d, o}=(1 / 10) \sum_{y=1}^{10} x_{d, y}$ is the total decadal mean and $\varepsilon_{d, o}=(1 / 10) \sum_{y=1}^{10} \varepsilon_{d, y}$ is the decadal mean of the residuals. Since $\mu_{d}$ is the population mean of $x_{d, o}$, it is potentially predictable. On the other hand, $\varepsilon_{d, y}$ is the yearly residual from the local linear trend $\mu_{d}+\beta_{d}(y-5.5)$, and it is unlikely to be predictable at the long range, as is $\varepsilon_{d, o}$.

\section{b. Removing the effect of the starting year}

Variability of a decadal mean series may depend on the starting year of the series. For example, for a sinusoidal series with a cycle of 20 years, the decadal mean variance is positive if the decadal mean series starts from the first year but vanishes if the decadal mean series starts from the fifth year. To achieve a robust result, the annual time series $\mathbf{x}$ within $D$ decades is reconstructed into 10 datasets with $D-1$ decades starting from the successive year $i=0, \ldots, 9$. Following Eq. (1), it can be expressed as

$$
x_{d, i+y}=\mu_{d, i}+\beta_{d, i}(y-5.5)+\varepsilon_{d, i+y} .
$$

In this study, it is assumed that the residuals of the 10 datasets are from a common AR(1) process. The common autocorrelation coefficient $\alpha$ is estimated by minimizing the sum of the -2 -ln-likelihood functions of the random variables $\left\{\nabla^{2} \varepsilon_{d, i+y}\right.$, $y=1, \ldots, 10\}$ given the outcome $\left\{\nabla^{2} x_{d, i+y}, y=3, \ldots, 10\right\}[\mathrm{Eq}$. (A6) of appendix A] over $d=1, \ldots, D$ and $i=0, \ldots, 9$.

Let $\mathbf{x}^{\prime}$ be another yearly time series with $D$ decades. The total covariance between two decadal running means $\mathbf{x}$ and $\mathbf{x}^{\prime}$ is defined as 


$$
\begin{aligned}
V\left(x_{d, i+o}, x_{d, i+o}^{\prime}\right)= & \frac{1}{10(D-2)} \sum_{j=0}^{9} \sum_{f=1}^{D-1}\left(x_{f, j+o}-x_{o, j+o}\right) \\
& \left(x_{f, j+o}^{\prime}-x_{o, j+o}^{\prime}\right) .
\end{aligned}
$$

The fast-decadal covariance between two running mean time series is estimated as

$$
V\left(\varepsilon_{d, i+o}, \varepsilon_{d, i+o}^{\prime}\right)=\frac{V\left(\varepsilon_{d, y}, \varepsilon_{d, y}^{\prime}\right)}{100}\left\{\sum_{z=1}^{9}(10-z)\left(\alpha^{z}+\alpha^{\prime z}\right)+10\right\},
$$

where

$$
V\left(\varepsilon_{d, y}, \varepsilon_{d, y}^{\prime}\right)=\frac{\sum_{j=0}^{9} \sum_{f=1}^{D-1} \sum_{z=3}^{10} \nabla^{2} x_{f, j+z} \nabla^{2} x_{f, j+z}^{\prime}}{80(D-1)\left(6-4 \alpha+4 \alpha^{\prime}+\alpha^{2}+\alpha^{\prime 2}\right)}
$$

(see appendix A for the proof).

Finally, the slow-decadal covariance is defined as

$$
V\left(\mu_{d, i}, \mu_{d, i}^{\prime}\right)=V\left(x_{d, i+o}, x_{d, i+o}^{\prime}\right)-V\left(\varepsilon_{d, i+o}, \varepsilon_{d, i+o}^{\prime}\right) .
$$

A significance test for the slow-decadal covariance is documented in appendix B.

Equations (6), (7), and (9) are used to construct the total, fast-decadal, and slow-decadal covariance matrices respectively, and the associated patterns of decadal variability can be derived from either an empirical orthogonal function analysis (EOF) or a singular value decomposition (SVD) analysis applied to each covariance matrix. Those derived using Eq. (6) will be referred to as the total decadal modes (TD-MODEs), those derived using Eq. (7) as the fast-decadal modes (FDMODEs) to indicate their relationship with fast-decadal variability, or noise, within the decade, and those using Eq. (9) will be referred to as the slow decadal modes (SD-MODEs); they represent the potentially predictable patterns of interdecadal variability.

We can also associate a time series with each of the three types of modes, being the projection of the yearly data onto the individual modes.

\section{c. Potentially predictability of decadal running means}

The decadal running means of the annual time series $\mathbf{x}$ can be expressed as

$$
\begin{aligned}
\overline{\mathbf{x}} \bumpeq & \left\{x_{1,0+o}, x_{1,1+o}, \ldots, x_{1,9+o}, x_{2,0+o}, x_{2,1+o}, \ldots, x_{2,9+o}, \ldots,\right. \\
& \left.x_{D-1,0+o}, x_{D-1,1+o}, \ldots, x_{D-1,9+o}\right\}
\end{aligned} .
$$

The potential predictability of the decadal running means $\bar{x}$, or the slow variance fraction, is defined as

$$
p_{\mathrm{dec}}=\frac{V\left(x_{d, i+o}\right)-V\left(\varepsilon_{d, i+o}\right)}{V\left(x_{d, i+o}\right)} .
$$

If the null assumption $p_{\mathrm{dec}}=0$ is true, then $x_{d, i+o}=\varepsilon_{d, i+o}$ for all $d=1, \ldots, D-1$ and $i=0, \ldots, 9$. Then

$$
\overline{\mathbf{x}}=\left\{\varepsilon_{1,0+o}, \varepsilon_{1,1+o}, \ldots, \varepsilon_{1,9+o}, \varepsilon_{2,0+o}, \varepsilon_{2,1+o}, \ldots, \varepsilon_{2,9+o}, \ldots,\right.
$$

$$
\left.\varepsilon_{D-1,0+o}, \varepsilon_{D-1,1+o}, \ldots, \varepsilon_{D-1,9+o}\right\} \stackrel{\wedge}{=}
$$

is a sample of the population of decadal running means of the AR(1) process with the first-order autocorrelation coefficient $\alpha$ and the variance $V\left(\varepsilon_{d, y}\right)$ estimated using Eq. (8). By successively applying Eq. (2), the $(s, t)$ entry (i.e., row $s$ and column $t$ ) of the covariance matrix (Petersen and Pedersen 2012) of the decadal running means (denoted by $\mathbf{V}_{\bar{\varepsilon}}$ ) is

$$
\mathbf{V}_{\bar{\varepsilon}}[s, t]=\frac{V\left(\varepsilon_{d, y}\right)}{100} \sum_{j=s}^{s+9} \sum_{i=t}^{t+9} \alpha^{|i-j|}, 1 \leq s, t \leq 10(D-1) .
$$

Since $\overline{\boldsymbol{\varepsilon}}^{\mathrm{T}} \mathbf{V}_{\bar{\varepsilon}}^{-1 / 2}$ are $10(D-1)$ independent random variables having the standard normal distribution, then the statistic $\overline{\mathbf{x}}^{\mathrm{T}} \mathbf{V}_{\bar{\varepsilon}}^{-1} \overline{\mathbf{x}}$ is distributed as $\chi^{2}[10(D-1)]$ [i.e., chi-square distribution with $10(D-1)$ degrees of freedom; Wilks 2011]. If the statistic $\overline{\mathbf{x}}^{\mathrm{T}} \mathbf{V}_{\bar{\varepsilon}}^{-1} \overline{\mathbf{x}}$ is larger than the $p$ value of $\chi^{2}[10(D-1)]$, the potential predictability is significantly larger than 0 at the $1-p$ significance level. Supplement A to this paper (see the online supplemental material) includes $\mathrm{R}$ code for implementing Eqs. (7)-(11).

Schneider and Held (2001) studied the predictability of local means to their residuals. This paper is devoted to the predictability of the implicit slow components [Eq. (5)] to the local (decadal) means. Moreover, the information matrices of the two studies are different. In the present study, the slow covariance [total covariance minus fast covariance Eq. (9)] is the information matrix and hence the first eigenvector of the information matrix explains the largest variance in the slow variability. If the principle of Schneider and Held (2001) is applied to the present study, the information matrix would be the fast covariance matrix times the inverse of the total covariance matrix, and hence the first eigenvector of the information matrix has the most significant predictability [i.e., Eq. (10)]. In the latter case, the leading modes have the largest predictability but may, or may not, explain a large amount of the variability. For the former case, the leading modes will have the largest variability in the slow component, which is also likely to be significantly predictable because they are associated with slow processes on decadal/multidecadal time scales.

\section{d. Why assume intradecadal linear trend}

To study the potential predictability of decadal means, Boer (2004) proposed the AR(1) assumption of Eq. (2), but did not consider the possibility of an intradecadal trend term. Also, Boer (2004) did not discuss how to estimate the autocorrelation coefficient $\alpha$ of the yearly residuals $\left\{\varepsilon_{d, y}\right\}$. How to do so is not obvious, because the residuals are not observable, and data $\left\{x_{d, y}=\mu_{d}+\varepsilon_{d, y}\right\}$ have to be used instead [see Trenberth (1984), Zheng (1996), and Zheng and Renwick (2001) for more detailed discussions]. In this study, the possibility of trends within decadal intervals are considered in our formulation, and an unbiased estimation, using the second-order difference operator for the autocorrelation coefficient $\alpha$ of the residuals in Eq. (2), is proposed.

If there are no trends within decadal intervals (i.e., $\beta_{d}=0$ ), the second-order difference operator [Eq. (3)] is not necessary, and it is more convenient to apply the first-order difference 
TABLE 1. Ensemble mean of the 1000 estimated autocorrelation coefficient $\alpha$.

\begin{tabular}{llcccc}
\hline \hline \multicolumn{1}{c}{ Data } & \multicolumn{1}{c}{ Methodology } & $\alpha=0.2$ & $\alpha=0.4$ & $\alpha=0.6$ & $\alpha=0.8$ \\
\hline$\beta_{d}=0$ & First-order difference & 0.198 & 0.398 & 0.599 & 0.797 \\
& Second-order difference & 0.198 & 0.398 & 0.601 & 0.796 \\
$\operatorname{Var}\left(\beta_{d}\right)=1$ & First-order difference & 0.252 & 0.464 & 0.649 & 0.831 \\
& Second-order difference & 0.198 & 0.398 & 0.601 & 0.796 \\
$\operatorname{Var}\left(\beta_{d}\right)=2$ & First-order difference & 0.279 & 0.526 & 0.695 & 0.859 \\
& Second-order difference & 0.198 & 0.398 & 0.601 & 0.796 \\
\hline
\end{tabular}

operator. In this case, $\alpha$ in Eq. (2) can be estimated by minimizing the sum of the -2 -ln-likelihood functions of the random variables $\left\{\nabla \varepsilon_{d, y}, y=2, \ldots, 10\right\}$ given the outcome $\left\{\nabla x_{d, y}, y=\right.$ $2, \ldots, 10\}$ [Eq. (C2) of appendix C] over $d=1, \ldots, D$. Moreover, Eq. (7) can still be used to estimate $V\left(\varepsilon_{d, o}\right)$, but $V\left(\varepsilon_{d, y}\right)$ in Eq. (7) should be estimated as (see appendix C)

$$
V\left(\varepsilon_{d, y}\right) \approx \frac{1}{18 D(1-\alpha)} \sum_{d=1}^{D} \sum_{y=1}^{9}\left(x_{d, y+1}-x_{d, y}\right)^{2} .
$$

To investigate the impact of ignoring $\beta_{d}$ on the estimated $\alpha$, the following simulation study is designed: 1000 samples of time series $\left\{\varepsilon_{d, y}, y=0,1, \ldots, 10, d=1, \ldots, 100\right\}$ are simulated for $\alpha=0.2,0.4,0.6,0.8$ with $V\left(\eta_{d, y}\right)=100$, using function "arima.sim" in the statistical package R. It is easy to prove that $V\left(\varepsilon_{d, y}\right)=V\left(\eta_{d, y}\right) /\left(1-\alpha^{2}\right)$. Then from Eq. (5), $V\left(\varepsilon_{d, o}\right)$ is $\left[1 /\left(1-\alpha^{2}\right)\right]\left\{\sum_{y=1}^{9} 2(10-y) \alpha^{y}+10\right\}$. The trends $\beta_{d}, d=1, \ldots$, 100 are simulated as white noise with variance 1 and 2 , respectively, using function "rnorm" in the statistical package R. The first-order difference approach and the second-order difference approach are applied to estimate the autocorrelation and the decadal variance of the year-to-year red-noise components. The results are shown in Tables 1 and 2 , respectively.

Table 1 shows that when $\beta_{d}=0, \alpha$ estimated using both the first-order difference approach and the second-order difference approach are unbiased. When intradecadal trends exist [i.e., $\left.\left.\operatorname{Var}\left(\beta_{d}\right)>0\right]\right)$, values of $\alpha$ estimated using the second-order difference approach are unchanged, but $\alpha$ using the first-order difference approach are larger than the true $\alpha$. Moreover, the estimated $\alpha$ for $\operatorname{Var}\left(\beta_{d}\right)=2$ is larger than that for $\operatorname{Var}\left(\beta_{d}\right)=1$. This indicates that the larger the trends within decadal intervals, the larger the overestimation of the autocorrelation coefficient. Table 2 also shows that when $\alpha$ is overestimated, the fastdecadal variance in the decadal means [i.e. $\left.V\left(\varepsilon_{d, o}\right)\right]$ tends to be overestimated.

\section{Case study 1: North Pacific SSTs}

a. Data

In this study, we have used data from the Extended Reconstructed Sea Surface Temperature, version 5 (ERSSTv5) for the 140-yr period 1879-2018 (Huang et al. 2017). The monthly mean ocean surface temperature has been mapped onto a $2^{\circ} \times 2^{\circ}$ grid covering the domain of the North Pacific (the Pacific north of the equator). Annual averages of the monthly mean values form the annual mean SST dataset used in this study.

\section{b. Analysis approach}

The nature of the Pacific decadal variability was investigated by d'Orgeville and Peltier (2007) based upon EOF analyses of low-pass filtered North Pacific SST observations over the last century. Their results suggested that Pacific decadal variability comprises a 20-yr quasi-periodic oscillation and a lowerfrequency component with a characteristic time scale of 60 years. The 20-yr quasi-periodic oscillation was identified as a phase locked signal at the eastern boundary of the Pacific basin, while the 60 -yr component of the Pacific decadal oscillation (PDO) is strongly time-lag correlated with the Atlantic multidecadal oscillation (AMO). In this section, the Pacific decadal variability is revisited using the new methodology proposed in this paper. First, EOF analysis was applied to the multisite SST decadal running means. The three leading total decadal modes (TD-MODEs) are shown in Figs. 1a-c and the principal component (PC) time series of the three leading total decadal modes are shown in Figs. 2a, 2c, and 2e, respectively.

TD-MODE 1 is associated with the global-mean SST trend. In fact, the PC time series of TD-MODE 1 (Fig. 2a) is significantly correlated (0.93) to the global SST anomaly (SSTA) time series (Fig. 2b), which is related to the release of volcanic aerosols, slow variations in solar and greenhouse gas forcing,

TABLE 2. Ensemble mean of the 1000 estimated $V\left(\varepsilon_{d, o}\right)$.

\begin{tabular}{|c|c|c|c|c|c|}
\hline Data & Methodology & $\alpha=0.2$ & $\alpha=0.4$ & $\alpha=0.6$ & $\alpha=0.8$ \\
\hline \multirow[t]{2}{*}{$\beta_{d}=0$} & First-order difference & 15.0 & 25.2 & 51.9 & 159.0 \\
\hline & Second-order difference & 15.0 & 25.0 & 50.5 & 149.4 \\
\hline \multirow[t]{2}{*}{$\operatorname{Var}\left(\beta_{d}\right)=1$} & First-order difference & 19.6 & 32.9 & 67.9 & 216.0 \\
\hline & Second-order difference & 15.0 & 25.0 & 50.5 & 149.4 \\
\hline \multirow[t]{3}{*}{$\operatorname{Var}\left(\beta_{d}\right)=2$} & First-order difference & 25.6 & 42.9 & 88.7 & 282.4 \\
\hline & Second-order difference & 15.0 & 25.0 & 50.5 & 149.4 \\
\hline & Theoretical & 15.0 & 25.1 & 50.9 & 150.8 \\
\hline
\end{tabular}


(a)

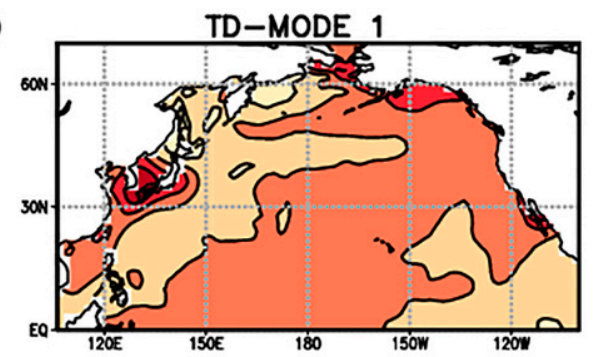

(b)

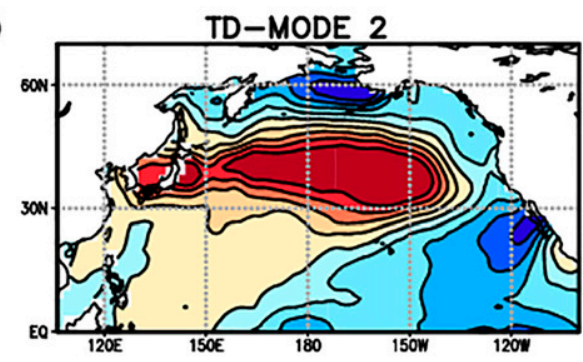

(c)

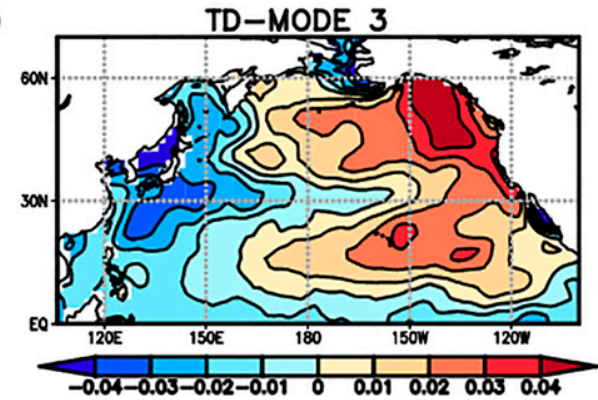

(d)

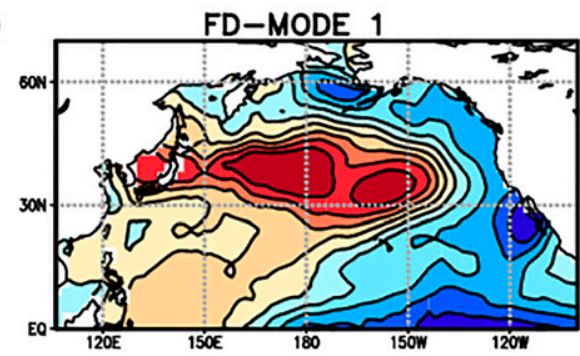

(e)

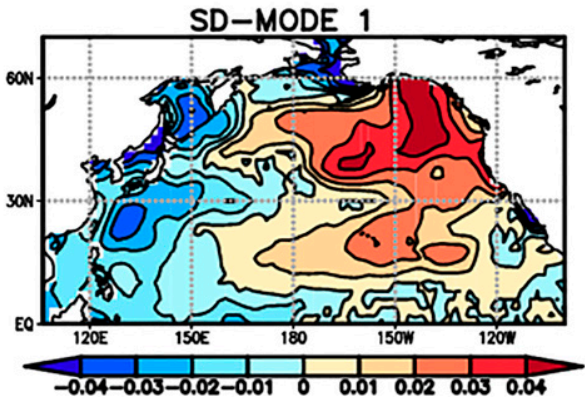

FIG. 1. (a)-(c) The three leading total modes, (d) the leading fast-decadal mode, and (e) the leading slow-decadal mode of North Pacific SST decadal variability. Loadings are dimensionless.

and other very slowly varying forcings over the 140 years of integration. To better understand the natural decadal variability, it would be better to remove such variability from the original SST data. For example, Trenberth and Shea (2006) removed the global-mean SST trend from the North Atlantic SST for the construction of the AMO index. In the present study, following Parker et al. (2007) and Yang et al. (2020), the impact of the global decadal-mean SST is removed by subtracting the product between TD-PC 1 and TD-MODE 1 from the global decadal running mean fields.

The approach documented in section 2 is then applied to the residual data. The leading FD-MODE and the leading SDMODE are shown in Figs. 1d and 1e, respectively.

\section{c. Fast-decadal mode}

The Pacific decadal oscillation (Mantua and Hare 2002; Folland et al. 2002) mode is defined as the first EOF of detrended annual SST in North Pacific (north of $20^{\circ} \mathrm{N}$ ) and is shown in Fig. 3a, and the PDO index is defined as the PC time series of the PDO mode. The covariance map between fast components of the decadal running mean PDO index (PDOI) and the decadal running mean SST is shown in Fig. 3b. FDMODE 1 (Fig. 1d) is very similar to Figs. 3a and 3b (with pattern correlations of 0.91 and 0.93 , respectively). The correlation between the decadal running mean of FD-MODE 1 time series and the PDO index is also very significant (with a correlation of 0.94). These facts indicate that the PDO fluctuations from the tangent linear trends are the major source of the decadal variability arising from the year-to-year fluctuations of North Pacific SST.

The present study suggests that the decadal running mean of the popular annual PDOI time series is statistically indistinguishable from a decadal running mean of a red-noise time series. This does not mean that the annual PDOI time series is red. In fact, it can be more predictable than persistence in the usual sense of decadal prediction (i.e., a forecast of the annual PDOI from the beginning of the decade for ranges up to 10 years). As an example, Boer and Sospedra-Alfonso (2019) showed that the annual PDOI can be best predicted within a 5 -yr time range (see the green bars of their Fig. 7b). However, this skill may be due to skill from predicting the intradecadal linear trends. Since the intradecadal linear trends were removed by the decadal mean low-pass filter, such prediction may not contribute much to the forecast skill for the decadal means. Although Boer and Sospedra-Alfonso (2019) did not study the forecast skill of the decadal mean PDOI, they showed 
(a) TD1 Timeseries

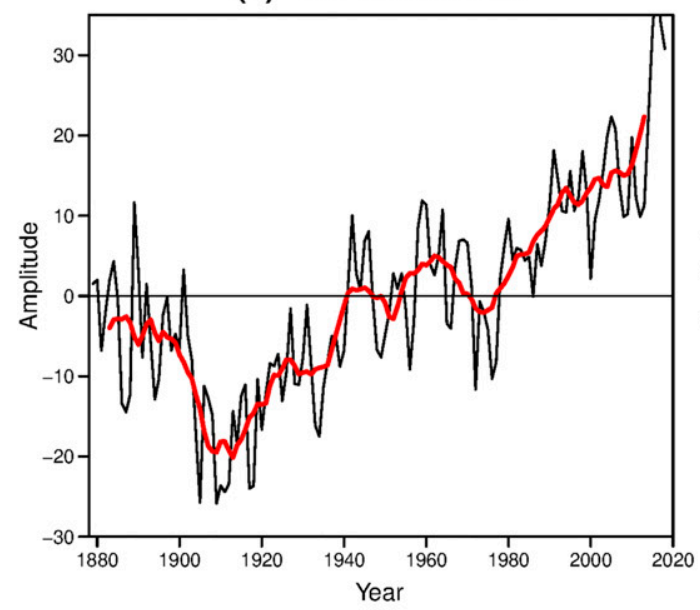

(c) TD2 Timeseries

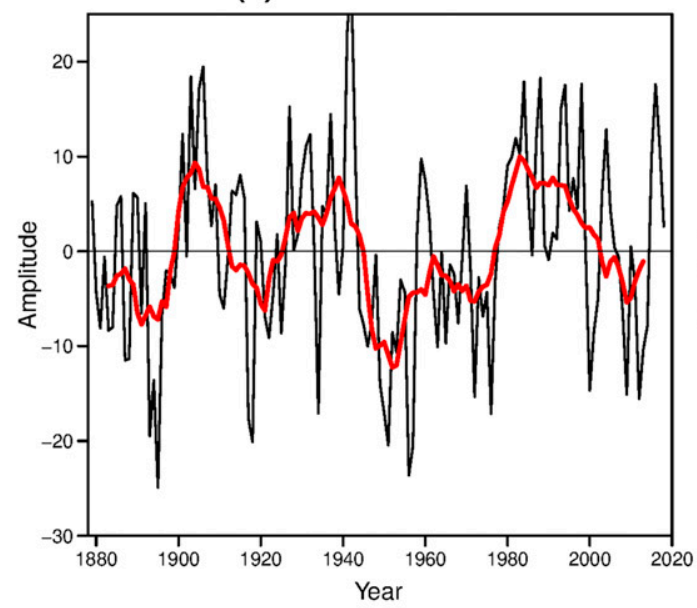

(e) TD3 Timeseries

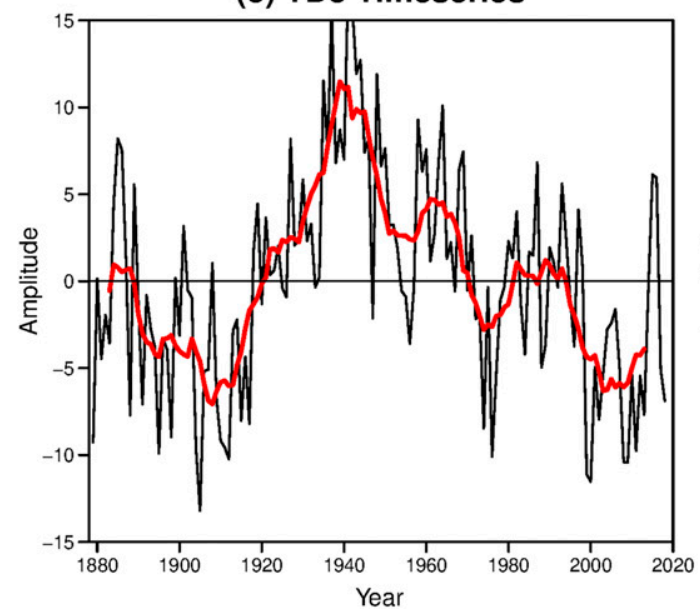

(b) Global SSTA Timeseries

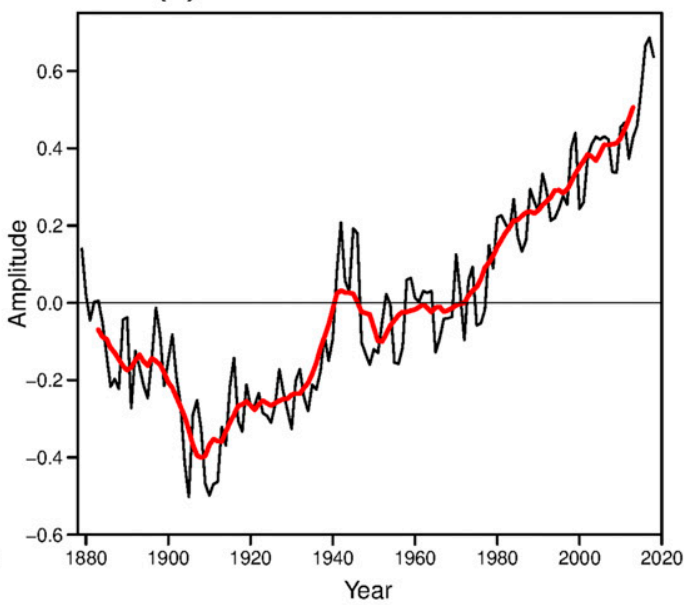

(d) FD1 Timeseries

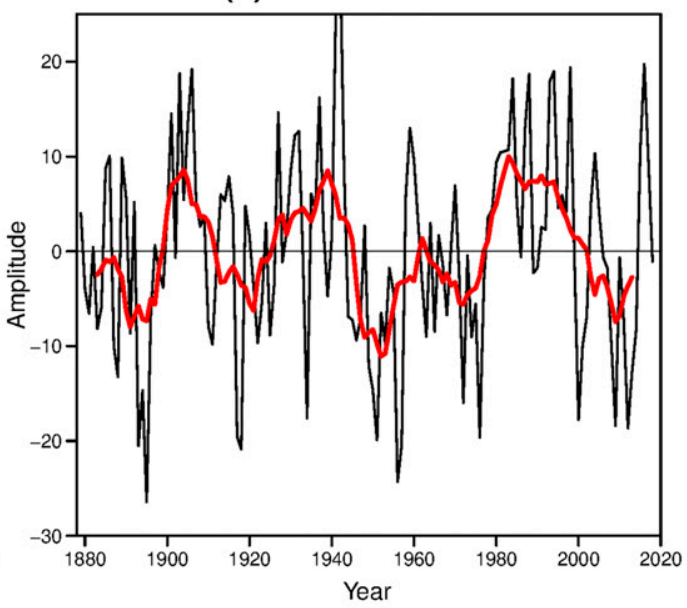

(f) SD1 Timeseries

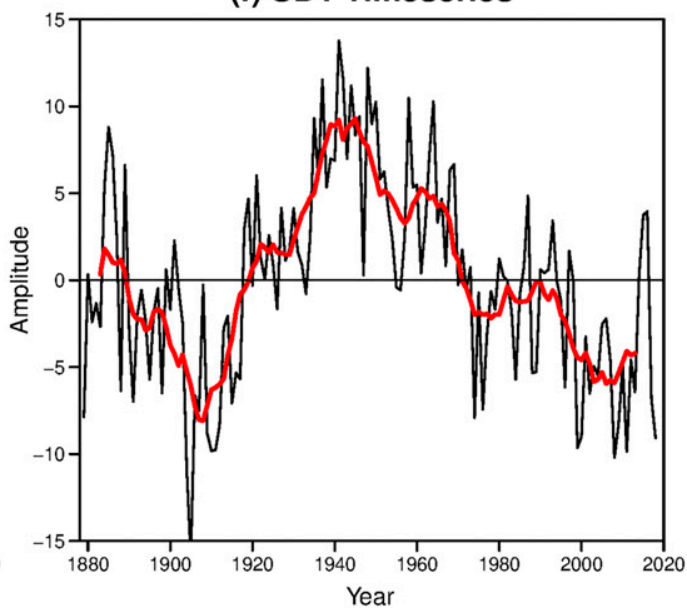

FIG. 2. PC time series of (a),(c),(e) the three leading total decadal modes, (b) the global SSTA time series, (d) the leading fast-decadal mode, and (f) the leading slow-decadal mode of North Pacific SST decadal variability $\left({ }^{\circ} \mathrm{C}\right)$. 
(a)

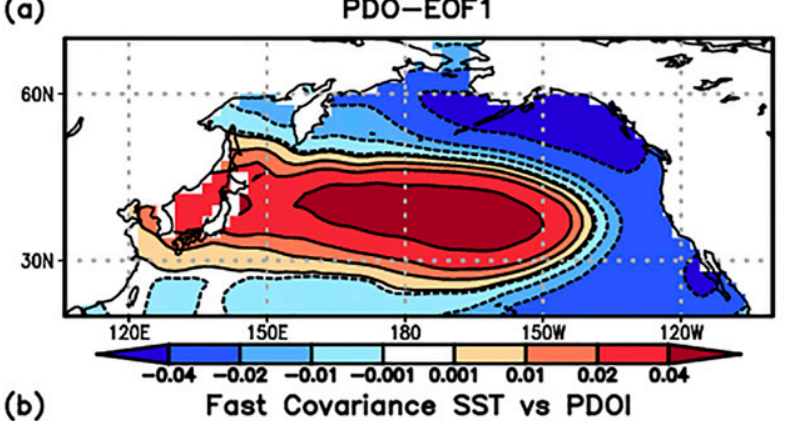

(b)
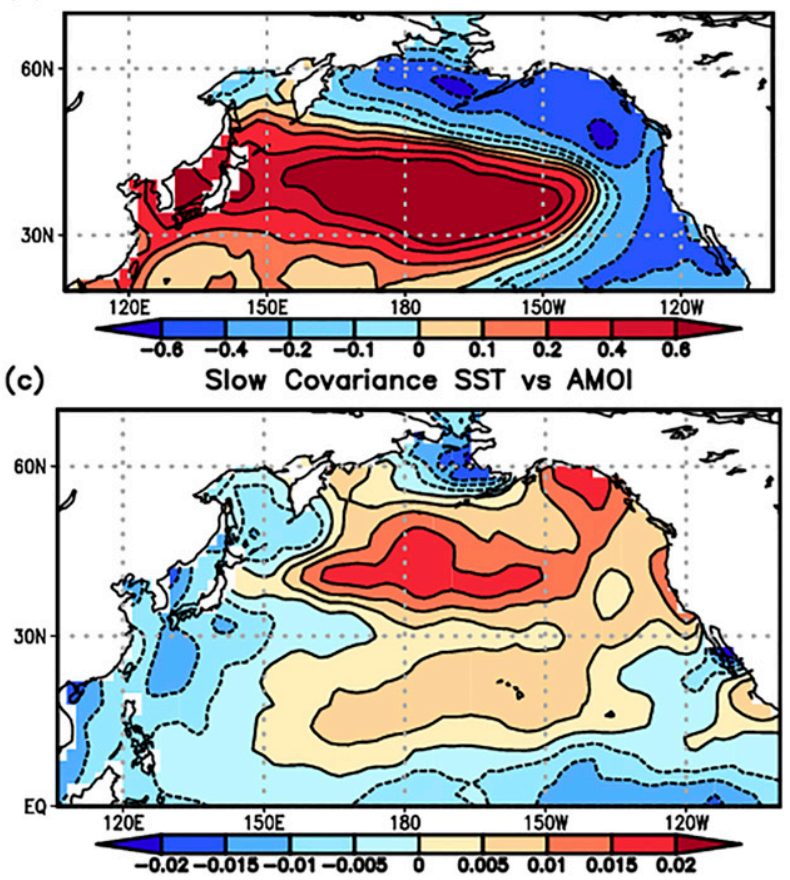

FIG. 3. (a) First EOF of detrended annual SST in North Pacific (PDO). (b) Fast-decadal covariance map between PDOI and SST. (c) Slow-decadal covariance map between 4-yr lead AMOI and SST.

that the average of correlations between the observations and the forecasts for time scales within 10 years is only 0.2 . Therefore, it is unlikely that the ensemble forecasts studied by Boer and Sospedra-Alfonso (2019) had a significant skill for the decadal mean PDOI.

\section{d. Slow-decadal mode}

The AMO has been identified as a coherent mode of natural variability occurring in the North Atlantic Ocean with an estimated period of 60-80 years. It is based upon the average anomalies of sea surface temperatures (SST) in the North Atlantic basin, typically over $0^{\circ}-80^{\circ} \mathrm{N}$. To remove the climate change signal from the AMO index, the global-mean SST anomaly time series was subtracted from the spatially averaged time series (Trenberth and Shea 2006).
The lagged slow-decadal covariances between the decadal running means of the AMO index and SD-PC 1 were calculated. It was found that the 4-yr lead AMO index has the most significant slow-decadal covariance $(0.31)$ with SD-PC 1 at statistical significance 0.01 (see appendix B). The covariance map between decadal running mean slow components of the 4-yr lead AMO index and SST is shown in Fig. 3c. It is very similar to the SD-MODE 1 with pattern correlation of 0.96 . Knight et al. (2005) found a similar pattern in their coupled model study. Therefore, SD-MODE 1 is likely to be forced by the AMO with lag about 4 years. SD-MODE 1 is associated with cooling in the western Pacific and warming in the east Pacific. This could be because a positive AMO corresponds to anomalous warm North Atlantic and cold South Atlantic SSTs, that leads to a weak Hadley cell in the Northern Hemisphere, resulting in a northward displacement of the intertropical convergence zone in the Pacific. These would reduce the North Pacific subtropical gyre and the Kuroshio (Wu et al. 2019). Parker et al. (2007) defined the AMO as the third covariance EOFs for 1891-2005 of low-pass-filtered SST (see their Fig. 6). Compared with the SD-MODE1, the positive SST loading of Parker et al. (2007) extended more south and eastward.

\section{Case study 2: Northern Hemisphere 1000-hPa geo- potential height}

\section{a. Data}

As a second example, we have used data from the 20CR 1000-hPa geopotential height (GPH) dataset for the 140 years 1876-2015 (Compo et al. 2011) over the Northern Hemisphere. These data appear on a $5^{\circ} \times 5^{\circ}$ latitude-longitude grid with a thinning of the longitude grid toward the pole in order to avoid biasing the analysis toward the higher latitudes (Frederiksen and Zheng 2004). Again, annual averages of the monthly mean values form the annual mean GPH dataset that is used in this study.

\section{b. Analysis approach}

An EOF analysis of the $1000-\mathrm{hPa}$ GPH decadal running means was conducted. The four leading TD-MODEs from an EOF analysis of the GPH decadal running means are shown in Figs. $4 \mathrm{a}-\mathrm{d}$; they explain $62 \%, 14 \%, 7 \%$, and $5 \%$ of the total decadal variance, respectively.

As for the leading SST TD-MODE 1, the PC time series of GPH TD-MODE 1 has a significant trend of $3 \mathrm{~m} \mathrm{yr}^{-1}$, and as a result explains a high $62 \%$ of GPH decadal variance. It has a correlation with the global SSTA time series (Fig. 2b) of 0.55 . The impact of the GPH trend has largest impact over the North Pacific and over the North Pole with largest loadings in these regions. Again, in order to better understand the natural decadal variability, we remove this trend variability from the original GPH data in same way as was done for the SST in section 3 .

In the next section, we discuss the leading GPH FD-MODEs and SD-MODEs and compare with well-known interannual and decadal climate indices. 
(a)

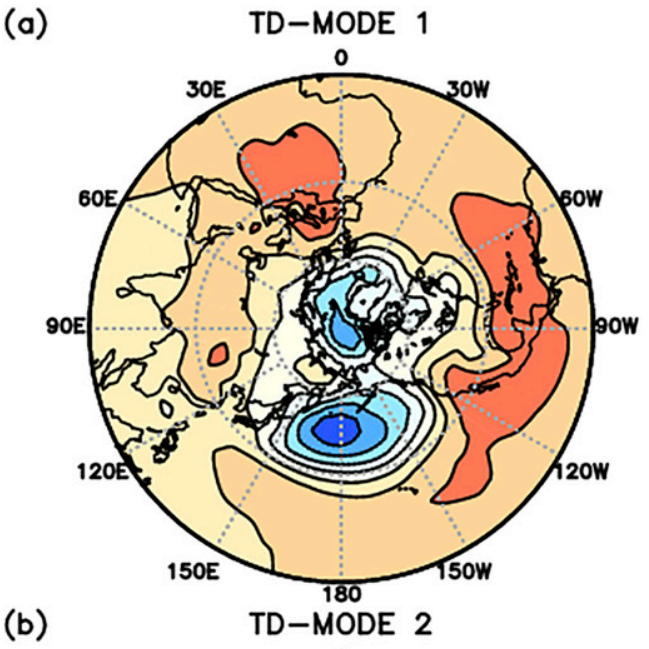

(b)

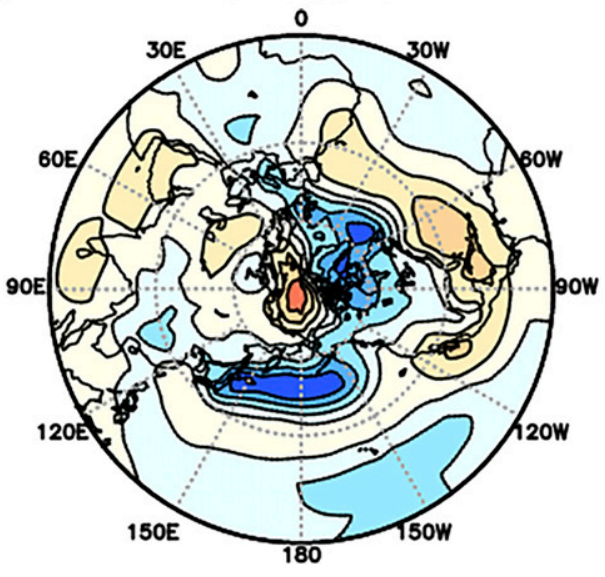

(c)

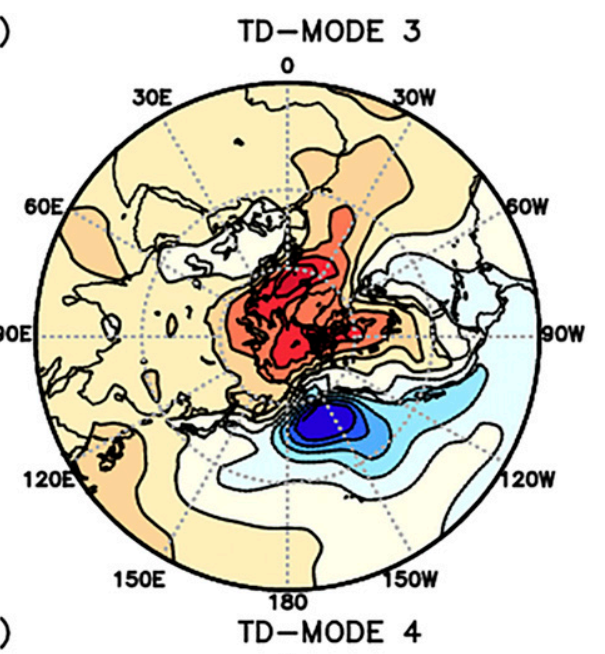

(d)

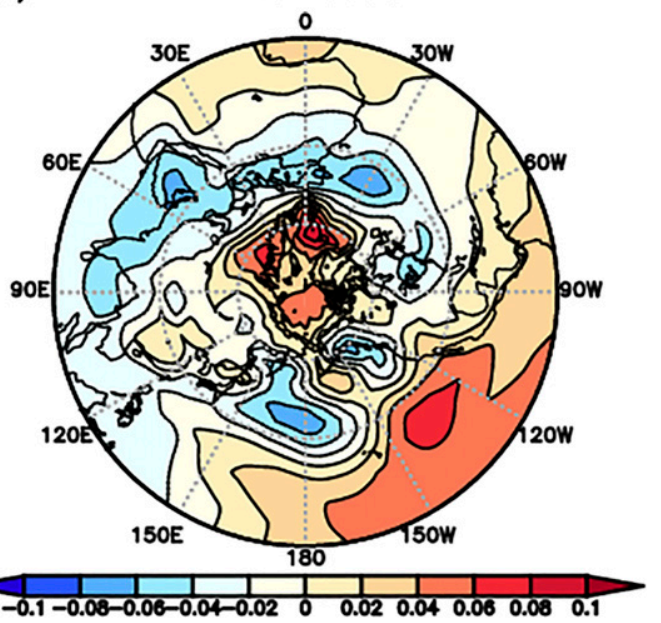

FIG. 4. (a)-(d) The leading TD-MODEs for 1000-hPa GPH. Units are dimensionless.

\section{c. Fast-decadal modes}

The three leading GPH FD-MODEs are shown in Figs. 5c-e and explain $38 \%, 13 \%$, and $11 \%$ of the fast decadal variance, respectively. FD-MODE 1 is very reminiscent of the northern annular mode (NAM)/Arctic Oscillation (AO)/North Atlantic Oscillation (NAO) (Barnston and Livezey 1987; Frederiksen and Zheng 2004). To explore this relationship, an annual NAM index was constructed based on that defined by $\mathrm{Li}$ and Wang (2003), but using the 1000-hPa GPH as a proxy for the sea level pressure (SLP). The index is defined here as the difference between the zonal average $1000-\mathrm{hPa}$ GPH at $35^{\circ}$ and $65^{\circ} \mathrm{N}$ for the period 1876-2015. The fast decadal covariance between this index and the $1000-\mathrm{hPa}$ GPH was then estimated using Eq. (7) and the result is shown in Fig. 6c. The pattern correlation between Figs. $6 \mathrm{c}$ and $5 \mathrm{c}$ is 0.81 , and indicates that this mode is associated with the fast decadal variation in the NAM index.

FD-MODE 2 has a pattern that is reminiscent of the east Atlantic (EA) pattern of interannual variability (Barnston and Livezey 1987; Frederiksen and Zheng 2004). To explore this, we calculated the interannual EOFs of the 20CR 500-hPa GPH over the period 1876-2015. EOF 6, from this analysis, has the structure of the EA mode seen in the two references. Again, the fast covariance between the PC time series of this EA mode and the 1000-hPa GPH (Fig. 6d) shows a similar structure to FD-MODE 2 (Fig. 5d), especially over the higher latitudes. The hemispheric pattern correlation is 0.39 , but rises to 0.5 if taken between $25^{\circ}$ and $90^{\circ} \mathrm{N}$.

Finally, FD-MODE 3 (Fig. 5e) has the largest loading in the North Pacific and has the largest pattern correlation with the fast decadal covariance of our PDOI (section 3 ) and the 1000-hPa GPH (Fig. 6e) of 0.74. This indicates that this mode is strongly associated with the fast decadal variability of the PDOI.

Lou et al. (2017), using the earlier methodology of Frederiksen et al. (2016), studied the slow and fast components of NH 500-hPa GPH and SLP in a 1000-yr model simulation for the period $850-1850$. They only considered the two leading fast modes, which, in both fields, were associated with the AO and PDO, and had similar patterns to those seen in our FD-MODEs 1 and 3. 
(a)

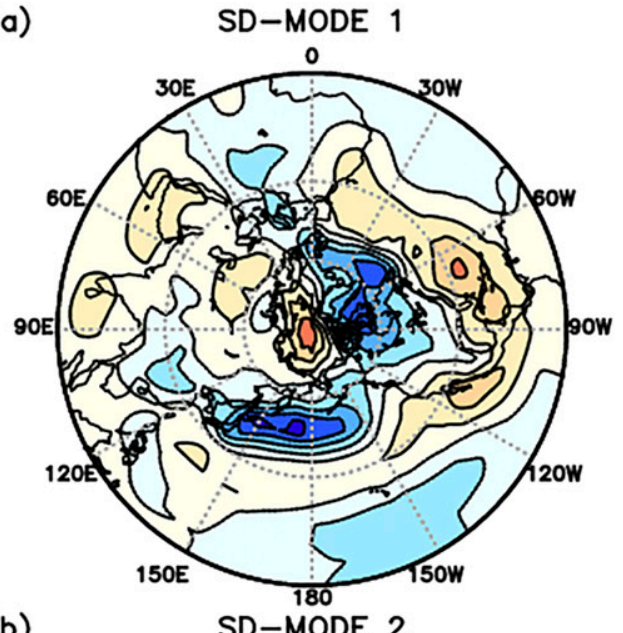

(b)

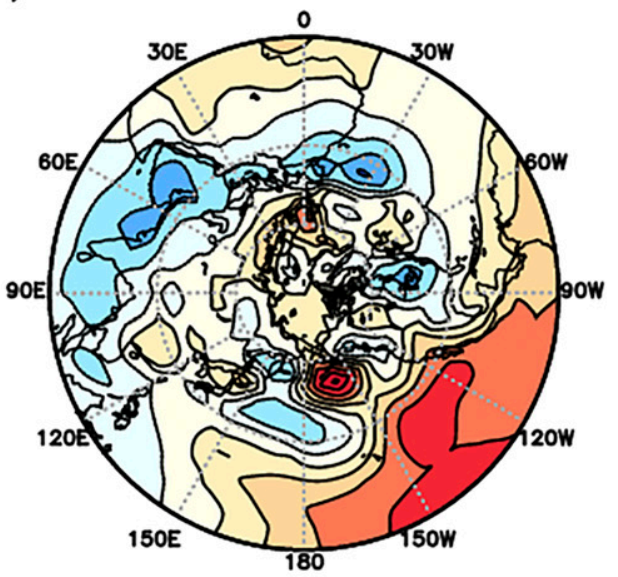

(c)

FD-MODE 1

(d)
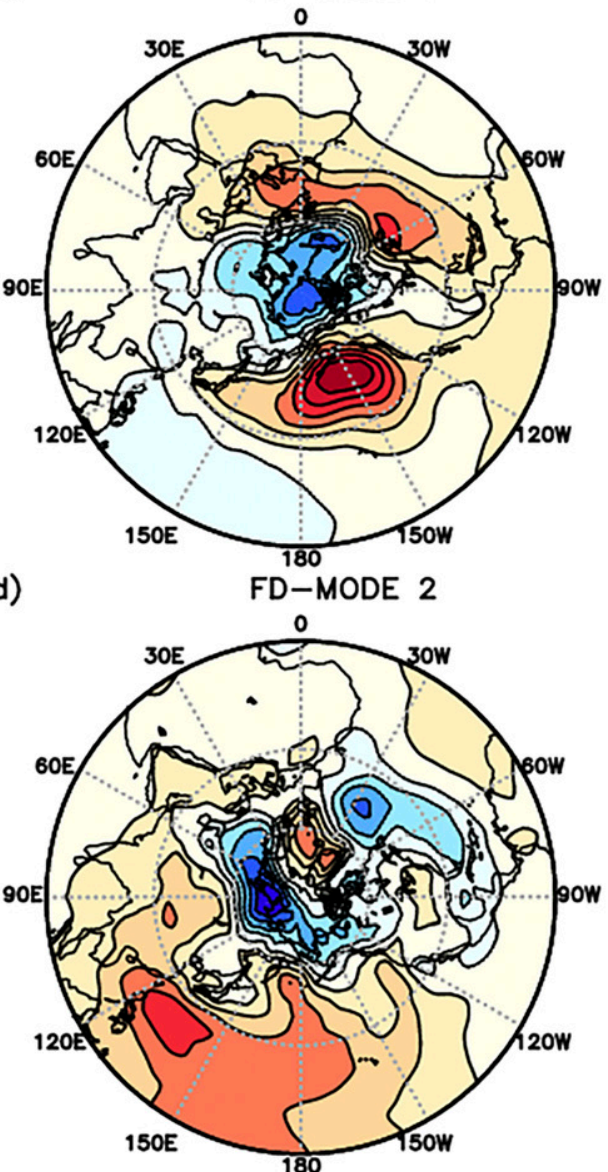

(e)
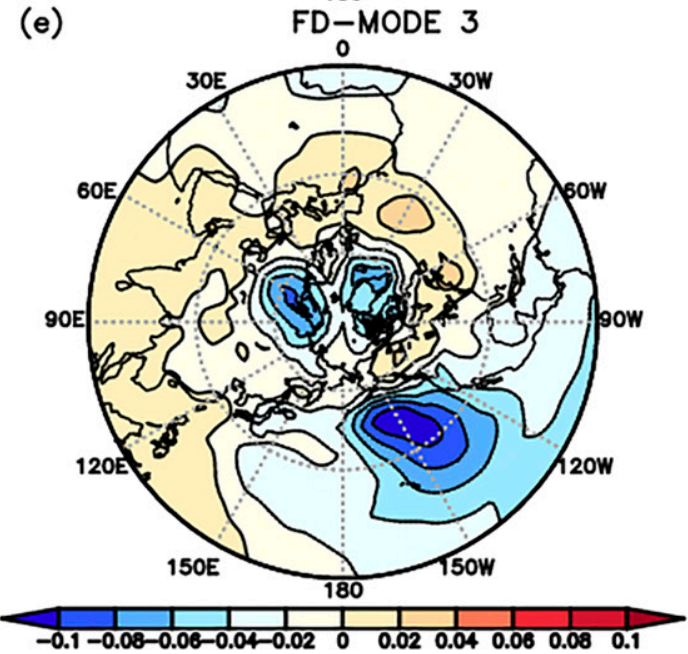

FIG. 5. (a),(b) The leading SD-MODEs and (c)-(e) the leading FD-MODEs for 1000-hPa GPH. Units are dimensionless.

\section{d. Slow-decadal mode}

The two leading SD-MODEs are shown in Figs. 5a and 5b, and they explain $51 \%$ and $20 \%$ of the slow decadal variance in the 1000-hPa GPH. In this study, the only climate indices that we have found to have a significant slow decadal variability relative to the total decadal variability are the AMOI and NAMI, with ratios of slow to total variance [Eq. (10)] of 0.83 
(a)

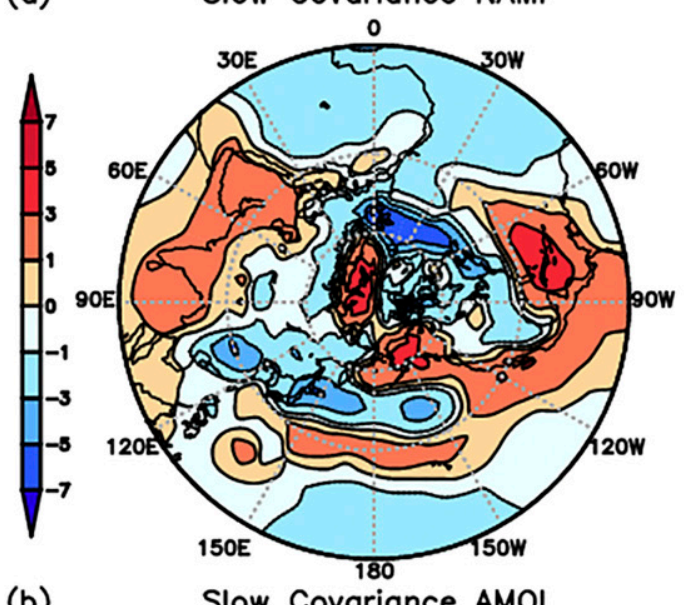

(b)

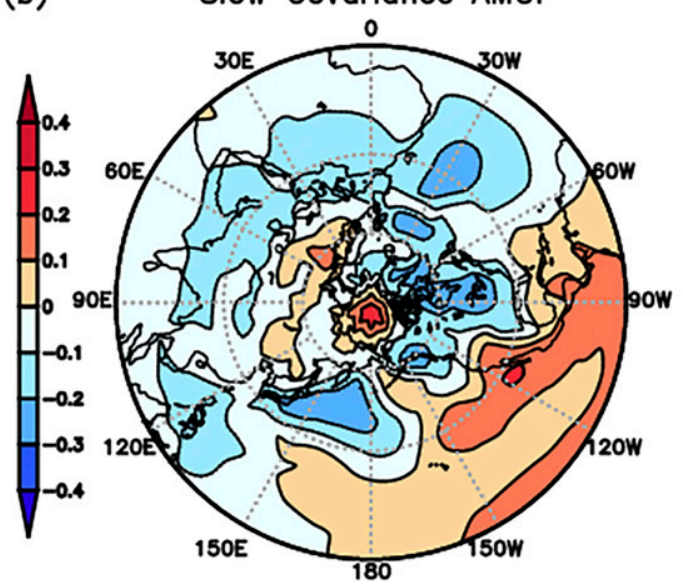

(c)

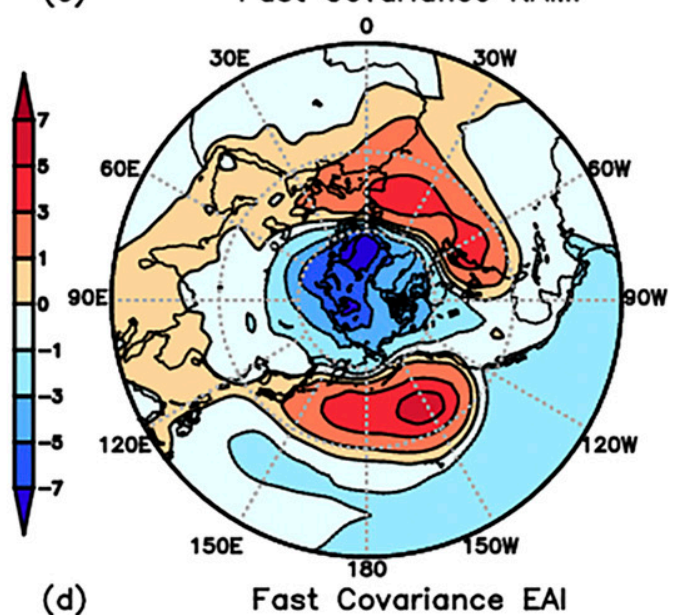

(d)

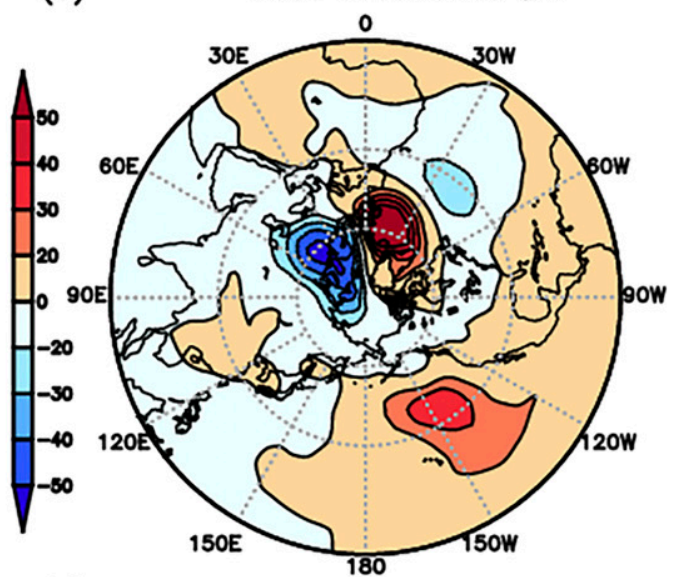

(e)

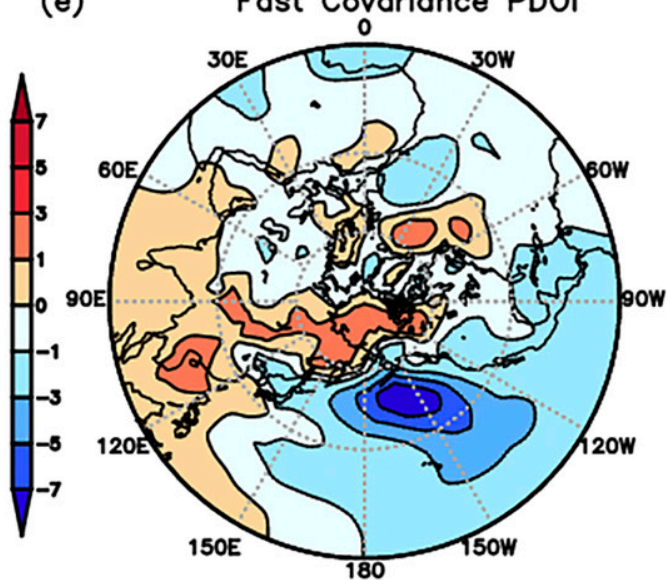

FIG. 6. (a),(b) The slow covariance between the $1000-\mathrm{hPa}$ GPH and NAMI $\left(\mathrm{m}^{2}\right)$ and AMOI $\left(\mathrm{m}^{\circ} \mathrm{C}\right)$, respectively, and (c)-(e) the fast covariance between the 1000-hPa GPH and NAMI $\left(\mathrm{m}^{2}\right)$, EAI $\left(\mathrm{m}^{2}\right)$, and PDOI $\left(\mathrm{m}{ }^{\circ} \mathrm{C}\right)$, respectively.

and 0.60 , with significance $>99 \%$ (section $2 c)$. So, it is interesting to see how these indices are related to our SD-MODEs.

Figure 6a shows the slow covariance between our NAMI and the $1000-\mathrm{hPa}$ GPH. It shows similar overall features to the pattern shown for SD-MODE 1, especially in the location of the maxima and minma in loadings. The pattern correlation between Figs. 5a and $6 \mathrm{a}$ is 0.59 , indicating that the leading slow mode has a large contribution from the slow decadal component of the NAMI. 
Figure $6 \mathrm{~b}$ shows the corresponding plot for the AMOI and the $1000-\mathrm{hPa}$ GPH. In this case, the pattern correlation with Fig. $5 \mathrm{~b}$ is 0.73 , indicating a close association between the slow decadal component of the AMOI and SD-MODE 2.

Lou et al. (2017), in their model study, also found two slow decadal modes associated with the AMO and the AO/NAM, with similar features to those seen here.

\section{Discussion and conclusions}

In this paper, the covariance matrix of multisite decadal data was decomposed into a fast-decadal component and a slow-decadal component. Then an EOF analysis was applied to both components to identify the sources of the multivariate decadal mean variabilities arising from physical processes with potentially predictable slow-decadal variabilities, and the sources of the multisite decadal mean variabilities arising from unpredictable year-to-year fluctuations from tangent linear trends. These modes have been shown to be associated with well-known climate indices representing interannual, decadal, and multidecadal climate variability. However, it should be pointed out that while these indices have a close association, in general it is unlikely that such simple indices will capture, in their entirety, the complex structures of the modes presented here.

There are two new improvements in our methodology compared with previous studies. First, an allowance has been made for the possibility that the residuals of yearly data anomalies from the decadal population mean may have a linear trend within any decadal interval. Although such linear trends do not change the decadal means because they are removed by the decadal mean filter, the simulation study demonstrated that ignoring such linear trends may overestimate the variability of the fast-decadal variance in the decadal means using the firstorder difference approach, which is unbiased if there are no such trends. The second-order difference approach was proposed to mitigate this problem.

Frederiksen et al. (2016) proposed another alternative methodology for estimating the fast-decadal variance of decadal means without considering the intradecadal trend. In their analysis, the autocorrelation was calculated using the residuals of yearly data from decadal running means. This methodology was also applied to the North Pacific SST and the results are shown in supplemental material $\mathrm{B}$. The horizontal structure of the FD-MODE 1 is similar to the fast covariance map of PDOI (Fig. 3b) and also the FD-MODE1 (Fig. 1d) of the current method. The SD-MODE 1 is similar to the slow covariance map of AMOI (Fig. 3c) and the current SDMODE1 shown in Fig. 1e. However, SD-MODE 2, not seen in the present study, is also similar to Fig. 3b, suggesting that the PDO is a driver for both slow and fast variability. However, it is inconsistent with the present study.

To investigate the reason for this, the methodology of Frederiksen et al. (2016) was applied to estimate the first-order autocorrelation of simulated red-noise time series. The results showed that the autocorrelations are underestimated, which leads to underestimations of the fast variability, but overestimations in the slow variability. Therefore, some fast variability (such as PDO) leaks to the slow variability. By using this alternative methodology, Frederiksen et al. (2016) and Lou et al. (2017) also identified the PDO as a driver of the slow variability. Therefore, results are sensitive to the methodologies applied.

Second, in order to avoid the possibility that the decomposition is sensitive to the initial starting year, in the shorter reanalysis data or observational data, the decomposition was applied to decadal running mean data instead of previously used decadal mean data. The decadal running mean filter is a special low-pass filter with 10 -yr length and equal weights. The results presented here also suggest that variability of low-pass filtered data arises not only from physical processes with frequencies longer than the bandpass frequency, but possibly also from physical processes with significant year-toyear fluctuations.

The EOF analysis proposed in the paper can better separate and explain the modes for multisite decadal running mean time series, compared with the traditional EOF analysis. For example, for the 1000-hPa GPH analysis, TD-MODE 3 (Fig. 4c) has a nonsignificant fraction of slow variance [Eq. (10)], indicating that it is likely to be predominantly a fast decadal mode. This mode has pattern correlations with the fast covariance patterns seen in Figs. $6 c$ and $6 e$, associated with the NAMI and PDOI, of -0.56 and 0.58 , respectively. So, it appears as though TD-MODE 3 is a mixture of the fast covariance of these two indices. Our methodology identified two separate FD-MODEs: FD-MODE 1 (Fig. 5c) associated with the fast decadal variability in the NAMI and FD-MODE 3 (Fig. 5e) associated with the PDOI. TD-MODE 2 (Fig. 4b) has a pattern correlation of 0.57 with the slow covariance pattern seen in Fig. 6a associated the slow component of NAMI. Without the concept of the slow component, it would be difficult to explain TD-MODE 2.

The proposed methodology for decadal running means can be easily modified to decompose the variabilities of other decadal low-pass filtered data, such as the 11-yr running average (Yang et al. 2020) and Chebyshev filter with a half-power period of 11 years (Parker et al. 2007). However, it is not recommended to apply this methodology to subdecadal running means, such as 4-yr running mean time series. The fast component for 4-yr running means could be better predicted by numenrical predictions [see the green bars of Fig. 7 in Boer and Sospedra-Alfonso (2019) for an example]. Moreover, half of the data information is lost in applying the second-order difference operator for 4-yr running means, whereas the loss is reduced to $1 / 5$ for the decadal running means.

Acknowledgments. This work was supported by the National Key R\&D Program of China (Grants 2016YFC0207703 and 2016YFA0600402) and the National Natural Science Foundation of China (41975115 and 41475091). The authors thank three reviewers for valuable comments that helped to improve the paper. 


\section{APPENDIX A}

Estimation of Fast-Decadal Covariance $V\left(\boldsymbol{\varepsilon}_{d, i+o}, \boldsymbol{\varepsilon}_{d, i+o}^{\prime}\right)$ When Trends Within Decadal Intervals Exist

From Eqs. (1), (3), and (4),

$$
\begin{aligned}
\nabla^{2} x_{d, y} & =\nabla\left(\nabla x_{d, y}\right)=\nabla\left(x_{d, y}-x_{d, y-1}\right) \\
& =\left(x_{d, y}-x_{d, y-1}\right)-\left(x_{d, y-1}-x_{d, y-2}\right) \\
& =\left(\beta_{d}+\varepsilon_{d, y}-\varepsilon_{d, y-1}\right)-\left(\beta_{d}+\varepsilon_{d, y-1}-\varepsilon_{d, y-2}\right) \\
& =\varepsilon_{d, y}-2 \varepsilon_{d, y-1}+\varepsilon_{d, y-2} \\
& =\left(\varepsilon_{d, y}-\varepsilon_{d, y-1}\right)-\left(\varepsilon_{d, y-1}-\varepsilon_{d, y-2}\right) \\
& =\nabla^{2} \varepsilon_{d, y} .
\end{aligned}
$$

Then

$$
\begin{aligned}
V\left(\nabla^{2} \varepsilon_{d, y}, \nabla^{2} \varepsilon_{d, y}^{\prime}\right)= & V\left(\nabla^{2} x_{d, y}, \nabla^{2} x_{d, y}^{\prime}\right) \\
\approx & \frac{1}{8 D} \sum_{d=1}^{D} \sum_{y=3}^{10}\left(x_{d, y}-2 x_{d, y-1}\right. \\
& \left.+x_{d, y-2}\right)\left(x_{d, y}^{\prime}-2 x_{d, y-1}^{\prime}+x_{d, y-2}^{\prime}\right) .
\end{aligned}
$$

Since by Eq. (2) $\eta_{d, y+n}$ and $\varepsilon_{d, y}$ are uncorrelated for any positive lag $n$,

$$
\begin{aligned}
E \varepsilon_{d, y+n} \varepsilon_{d, y}^{\prime} & =E\left(\alpha^{n} \varepsilon_{d, y}+\alpha^{n-1} \eta_{d, y+1}+\cdots+\alpha \eta_{d, y+n-1}+\eta_{d, y+n}\right) \varepsilon_{d, y}^{\prime} \\
& =V\left(\varepsilon_{d, y}, \varepsilon_{d, y}^{\prime}\right) \alpha^{n} .
\end{aligned}
$$

Then

$$
\begin{aligned}
& V\left(\nabla^{2} \varepsilon_{d, y}, \nabla^{2} \varepsilon_{d, y}^{\prime}\right) \\
&= E\left(\varepsilon_{d, y}-2 \varepsilon_{d, y-1}+\varepsilon_{d, y-2}\right)\left(\varepsilon_{d, y}^{\prime}-2 \varepsilon_{d, y-1}^{\prime}+\varepsilon_{d, y-2}^{\prime}\right) \\
&= E \varepsilon_{d, y} \varepsilon_{d, y}^{\prime}-2 E \varepsilon_{d, y} \varepsilon_{d, y-1}^{\prime}+E \varepsilon_{d, y} \varepsilon_{d, y-2}^{\prime} \\
&-2 E \varepsilon_{d, y-1} \varepsilon_{d, y}^{\prime}+4 E \varepsilon_{d, y-1} \varepsilon_{d, y-1}^{\prime}-2 E \varepsilon_{d, y-1} \varepsilon_{d, y-2}^{\prime} \\
&+E \varepsilon_{d, y-2} \varepsilon_{d, y}^{\prime}-2 E \varepsilon_{d, y-2} \varepsilon_{d, y-1}^{\prime}+E \varepsilon_{d, y-2} \varepsilon_{d, y-2}^{\prime} \\
&= V\left(\varepsilon_{d, y}, \varepsilon_{d, y}^{\prime}\right)\left(1-2 \alpha+\alpha^{2}-2 \alpha^{\prime}+4-2 \alpha+\alpha^{\prime 2}-2 \alpha^{\prime}+1\right) \\
&= V\left(\varepsilon_{d, y}, \varepsilon_{d, y}^{\prime}\right)\left(6-4 \alpha-4 \alpha^{\prime}+\alpha^{2}+\alpha^{\prime 2}\right) .
\end{aligned}
$$

Using Eq. (2), the $i-j$ entry of the covariance matrix of $\left(\varepsilon_{d, 1}\right.$, $\left.\varepsilon_{d, 2}, \ldots, \varepsilon_{d, 10}\right)\left(\right.$ denoted as $\left.\mathbf{V}_{\varepsilon}\right)$ is $V\left(\varepsilon_{d, y}\right) \alpha^{|i-j|}$, where

$$
V\left(\varepsilon_{d, y}\right) \approx \frac{1}{8(D-1)\left(6-8 \alpha+2 \alpha^{2}\right)} \sum_{f=1}^{D-1} \sum_{z=3}^{10}\left(x_{f, z}-2 x_{f, z-1}+x_{f, z-2}\right)^{2}
$$

by setting $\varepsilon_{d, y}^{\prime}=\varepsilon_{d, y}$ and using Eqs. (A2) and (A4).

Using Eq. (A1), the covariance matrix of $\left(\nabla^{2} \varepsilon_{d, 3}, \nabla^{2} \varepsilon_{d, 4}, \ldots\right.$, $\left.\nabla^{2} \varepsilon_{d, 10}\right)^{\mathrm{T}}$ is

$$
\begin{aligned}
& \mathbf{V}_{\nabla^{2} \varepsilon}=E\left\{\left(\varepsilon_{d, 3}-2 \varepsilon_{d, 2}+\varepsilon_{d, 1}, \varepsilon_{d, 4}-2 \varepsilon_{d, 3}+\varepsilon_{d, 2}, \ldots, \varepsilon_{d, 10}-2 \varepsilon_{d, 9}+\varepsilon_{d, 8}\right)^{\mathrm{T}}\right. \\
& \left.\left(\varepsilon_{d, 3}-2 \varepsilon_{d, 2}+\varepsilon_{d, 1}, \varepsilon_{d, 4}-2 \varepsilon_{d, 3}+\varepsilon_{d, 2}, \ldots, \varepsilon_{d, 10}-2 \varepsilon_{d, 9}+\varepsilon_{d, 8}\right)\right\} \\
& =E\left(\varepsilon_{d, 3}, \varepsilon_{d, 4}, \ldots, \varepsilon_{d, 10}\right)^{\mathrm{T}}\left(\varepsilon_{d, 3}, \varepsilon_{d, 4}, \ldots, \varepsilon_{d, 10}\right) \\
& -2 E\left(\varepsilon_{d, 3}, \varepsilon_{d, 4}, \ldots, \varepsilon_{d, 10}\right)^{\mathrm{T}}\left(\varepsilon_{d, 2}, \varepsilon_{d, 3}, \ldots, \varepsilon_{d, 9}\right) \\
& +E\left(\varepsilon_{d, 3}, \varepsilon_{d, 4}, \ldots, \varepsilon_{d, 10}\right)^{\mathrm{T}}\left(\varepsilon_{d, 1}, \varepsilon_{d, 2}, \ldots, \varepsilon_{d, 8}\right) \\
& -2 E\left(\varepsilon_{d, 2}, \varepsilon_{d, 3}, \ldots, \varepsilon_{d, 9}\right)^{\mathrm{T}}\left(\varepsilon_{d, 3}, \varepsilon_{d, 4}, \ldots, \varepsilon_{d, 10}\right) \\
& +4 E\left(\varepsilon_{d, 2}, \varepsilon_{d, 3}, \ldots, \varepsilon_{d, 9}\right)^{\mathrm{T}}\left(\varepsilon_{d, 2}, \varepsilon_{d, 3}, \ldots, \varepsilon_{d, 9}\right) \\
& -2 E\left(\varepsilon_{d, 2}, \varepsilon_{d, 3}, \ldots, \varepsilon_{d, 9}\right)^{\mathrm{T}}\left(\varepsilon_{d, 1}, \varepsilon_{d, 2}, \ldots, \varepsilon_{d, 8}\right) \\
& +E\left(\varepsilon_{d, 1}, \varepsilon_{d, 2}, \ldots, \varepsilon_{d, 8}\right)^{\mathrm{T}}\left(\varepsilon_{d, 3}, \varepsilon_{d, 4}, \ldots, \varepsilon_{d, 10}\right) \\
& -2 E\left(\varepsilon_{d, 1}, \varepsilon_{d, 2}, \ldots, \varepsilon_{d, 8}\right)^{\mathrm{T}}\left(\varepsilon_{d, 2}, \varepsilon_{d, 3}, \ldots, \varepsilon_{d, 9}\right) \\
& +E\left(\varepsilon_{d, 1}, \varepsilon_{d, 2}, \ldots, \varepsilon_{d, 8}\right)^{\mathrm{T}}\left(\varepsilon_{d, 1}, \varepsilon_{d, 2}, \ldots, \varepsilon_{d, 8}\right) s
\end{aligned}
$$

where terms $E\left(\varepsilon_{d, i} \varepsilon_{d, j}\right)$ appearing in this expression are equal to $V\left(\varepsilon_{d, y}\right) \alpha^{|i-j|}$ as shown above.

The autocorrelation coefficient $\alpha$ be estimated through minimizing the sum of the -2 -log-likelihood function of the random variables $\left\{\nabla^{2} \varepsilon_{d, i+y}, y=1, \ldots, 10\right\}$ given the outcome $\left\{\nabla^{2} x_{d, i+y}, y=1, \ldots, 10\right\}$, that is,

$$
\begin{gathered}
\ln \left|\mathbf{V}_{\nabla^{2} \varepsilon}\right|+\left(\nabla^{2} x_{d, i+3}, \nabla^{2} x_{d, i+4}, \ldots, \nabla^{2} x_{d, i+10}\right) \\
\mathbf{V}_{\nabla^{2} \varepsilon}^{-1}\left(\nabla^{2} x_{d, i+3}, \nabla^{2} x_{d, i+4}, \ldots, \nabla^{2} x_{d, i+10}\right)^{\mathrm{T}},
\end{gathered}
$$

over $d=1, \ldots, D-1$ and $i=0, \ldots, 9$.

Following the proof of Eq. (A5), the covariance between $\varepsilon_{d, i+y}$ and $\varepsilon_{d, i+y}^{\prime}$ is

$$
V\left(\varepsilon_{d, i+y}, \varepsilon_{d, i+y}^{\prime}\right) \approx \frac{\sum_{j=0}^{9} \sum_{f=1}^{D-1} \sum_{z=3}^{10}\left(x_{f, j+\mathrm{z}}-2 x_{f, j+\mathrm{z}-1}+x_{f, j+\mathrm{z}-2}\right)\left(x_{f, j+\mathrm{z}}^{\prime}-2 x_{f, j+\mathrm{z}-1}^{\prime}+x_{f, j+\mathrm{z}-2}^{\prime}\right)}{80(D-1)\left(6-4 \alpha-4 \alpha^{\prime}+\alpha^{2}+\alpha^{\prime 2}\right)} .
$$

Finally, following Eq. (2) the covariance of the two decadal moving average residuals is

$$
\begin{aligned}
V\left(\varepsilon_{d, i+o}, \varepsilon_{d, i+o}^{\prime}\right) & =\frac{1}{100}\left\{\sum_{z=1}^{10} \sum_{z^{\prime}=1}^{10} E \varepsilon_{d, i+z} \varepsilon_{d, i+z^{\prime}}^{\prime}\right\} \\
& =\frac{1}{100}\left\{\sum_{z>z^{\prime}} E \varepsilon_{d, i+z} \varepsilon_{d, i+z^{\prime}}^{\prime}+\sum_{z<z^{\prime}} E \varepsilon_{d, i+z} \varepsilon_{d, i+z^{\prime}}^{\prime}+\sum_{z=1}^{10} E \varepsilon_{d, i+z} \varepsilon_{d, i+z}^{\prime}\right\} \\
& =\frac{V\left(\varepsilon_{d, i+y}, \varepsilon_{d, i+y}^{\prime}\right)}{100}\left\{\sum_{z=1}^{9}(10-z)\left(\alpha^{z}+\alpha^{\prime z}\right)+10\right\}
\end{aligned}
$$




\section{APPENDIX B}

\section{A Significance Test of Slow-Decadal Covariances}

Under the null hypothesis a slow-decadal covariance $V\left(x_{d, i+o}, x_{d, i+o}^{\prime}\right)-V\left(\varepsilon_{d, i+o}, \varepsilon_{d, i+o}^{\prime}\right)$ [see Eq. (9)] is zero, then the partial -2-ln-likelihood ratio statistic

$$
\begin{aligned}
& \sum_{d=1}^{D} \sum_{i=0}^{9}\left(x_{d, i+o}-x_{o, i+o}, x_{d, i+o}^{\prime}-x_{o, i+o}^{\prime}\right) \mathbf{V}_{0}^{-1}\left(x_{d, i+o}\right. \\
& \left.-x_{o, i+o}, x_{d, i+o}^{\prime}-x_{o, i+o}^{\prime}\right)^{\mathrm{T}}+\ln \left|\mathbf{V}_{o}\right| \\
& -\sum_{d=1}^{D} \sum_{i=0}^{9}\left(x_{d, i+o}-x_{o, i+o}, x_{d, i+o}^{\prime}-x_{o, i+o}^{\prime}\right) \mathbf{V}^{-1}\left(x_{d, i+o}\right. \\
& \left.-x_{o, i+o}, x_{d, i+o}^{\prime}-x_{o, i+o}^{\prime}\right)^{\mathrm{T}}-\ln |\mathbf{V}|
\end{aligned}
$$

is distributed as $\chi^{2}(1)$, where

$$
\begin{aligned}
& \mathbf{V}_{0}=\left[\begin{array}{ll}
V\left(x_{d, i+o}\right) & V\left(\varepsilon_{d, i+o}, \varepsilon_{d, i+o}^{\prime}\right) \\
V\left(\varepsilon_{d, i+o}, \varepsilon_{d, i+o}^{\prime}\right) & V\left(x_{d, i+o}^{\prime}\right)
\end{array}\right], \\
& \mathbf{V}=\left[\begin{array}{ll}
V\left(x_{d, i+o}\right) & V\left(x_{d, i+o}, x_{d, i+o}^{\prime}\right) \\
V\left(x_{d, i+o}, x_{d, i+o}^{\prime}\right) & V\left(x_{d, i+o}^{\prime}\right)
\end{array}\right] .
\end{aligned}
$$

If the statistic is greater than the $1-\alpha$ critical value, then the null hypothesis is rejected at the $\alpha$ significant level.

\section{APPENDIX C}

\section{Estimation of Fast-Decadal Covariance $V\left(\varepsilon_{d, i+o}, \boldsymbol{\varepsilon}_{d, i+o}^{\prime}\right)$ When There Are No Intradecadal Trends}

In the case of no linear trend within any decadal interval (i.e., $\beta_{d}=0$ for all $d$ ) the first-order difference

$$
\nabla x_{d, y}=x_{d, y}-x_{d, y-1}=\varepsilon_{d, y}-\varepsilon_{d, y-1}=\nabla \varepsilon_{d, y} .
$$

The sample variance of $\nabla x_{d, y}$ is

$$
\begin{aligned}
\frac{1}{9 D} \sum_{d=1}^{D} \sum_{y=1}^{9}\left(x_{d, y+1}-x_{d, y}\right)^{2} & \approx E\left[\left(\varepsilon_{d, y+1}-\varepsilon_{d, y}\right)^{2}\right] \\
& =E \varepsilon_{d, y+1}^{2}-2 E \varepsilon_{d, y+1} \varepsilon_{d, y}+E \varepsilon_{d, y}^{2} \\
& =2 V\left(\varepsilon_{d, y}\right)(1-\alpha) .
\end{aligned}
$$

Therefore

$$
V\left(\varepsilon_{d, y}\right) \approx \frac{1}{18 D(1-\alpha)} \sum_{d=1}^{D} \sum_{y=1}^{9}\left(x_{d, y+1}-x_{d, y}\right)^{2}
$$

is a function of $\alpha$.

The covariance matrix of $\left(\nabla \varepsilon_{d, 2}, \nabla \varepsilon_{d, 3}, \ldots, \nabla \varepsilon_{d, 10}\right)^{\mathrm{T}}$ is

$$
\begin{aligned}
& \mathrm{V}_{\nabla \varepsilon}=E\left(\varepsilon_{d, 2}-\varepsilon_{d, 1}, \varepsilon_{d, 3}-\varepsilon_{d, 2}, \ldots, \varepsilon_{d, 10}-\varepsilon_{d, 9}\right)^{\mathrm{T}}\left(\varepsilon_{d, 2}-\varepsilon_{d, 1}, \varepsilon_{d, 3}-\varepsilon_{d, 2}, \ldots, \varepsilon_{d, 10}-\varepsilon_{d, 9}\right) \\
& =E\left(\varepsilon_{d, 2}, \varepsilon_{d, 3}, \ldots, \varepsilon_{d, 10}\right)^{\mathrm{T}}\left(\varepsilon_{d, 2}, \varepsilon_{d, 3}, \ldots, \varepsilon_{d, 10}\right) \\
& -E\left(\varepsilon_{d, 2}, \varepsilon_{d, 3}, \ldots, \varepsilon_{d, 10}\right)^{\mathrm{T}}\left(\varepsilon_{d, 1}, \varepsilon_{d, 2}, \ldots, \varepsilon_{d, 9}\right) \\
& -E\left(\varepsilon_{d, 1}, \varepsilon_{d, 2}, \ldots, \varepsilon_{d, 9}\right)^{\mathrm{T}}\left(\varepsilon_{d, 2}, \varepsilon_{d, 3}, \ldots, \varepsilon_{d, 10}\right) \\
& +E\left(\varepsilon_{d, 1}, \varepsilon_{d, 2}, \ldots, \varepsilon_{d, 9}\right)^{\mathrm{T}}\left(\varepsilon_{d, 1}, \varepsilon_{d, 2}, \ldots, \varepsilon_{d, 9}\right)
\end{aligned}
$$

where terms $E\left(\varepsilon_{d, i} \varepsilon_{d, j}\right)$ appearing in this expression are equal to $V\left(\varepsilon_{d, y}\right) \alpha^{|i-j|}$ where $V\left(\varepsilon_{d, y}\right)$ is given by Eq. (C1). Therefore, $\alpha$ can be estimated through minimizing the -2-ln-likelihood:

$$
\begin{gathered}
-2 \ln \operatorname{Pr}_{\alpha}\left(\nabla \varepsilon_{d, y}=\nabla x_{d, y} ; y=2, \ldots, 10, d=1, \ldots, D\right)=D \ln \left(\mathbf{V}_{\nabla \varepsilon}\right) \\
+\sum_{d=1}^{D}\left(\nabla x_{d, 2}, \nabla x_{d, 3}, \ldots, \nabla x_{d, 10}\right) \mathbf{V}_{\nabla \varepsilon}^{-1}\left(\nabla x_{d, 2}, \nabla x_{d, 3}, \ldots, \nabla x_{d, 10}\right)^{\mathrm{T}} .
\end{gathered}
$$

\section{REFERENCES}

Allen, M., J. Mitchell, and P. Stott, 2013: Test of a decadal climate forecast. Nat. Geosci., 6, 243-244, https://doi.org/10.1038/ngeo1788.

Barnston, A. G., and R. E. Livezey, 1987: Classification, seasonality and persistence of low-frequency atmospheric circulation patterns. Mon. Wea. Rev., 115, 1083-1126, https://doi.org/ 10.1175/1520-0493(1987)115<1083:CSAPOL > 2.0.CO;2.

Boer, G. J., 2004: Long time-scale potential predictability in an ensemble of coupled climate models. Climate Dyn., 23, 29-44, https://doi.org/10.1007/s00382-004-0419-8.
, 2009: Changes in interannual variability and decadal potential predictability under global warming. J. Climate, 22, 30983109, https://doi.org/10.1175/2008JCLI2835.1.

— Pacific Decadal Oscillation (PDO) in a decadal prediction experiment. Climate Dyn., 53, 5763-5775, https://doi.org/ 10.1007/s00382-019-04896-w.

Compo, G. P., and Coauthors, 2011: The Twentieth Century Reanalysis Project. Quart. J. Roy. Meteor. Soc., 137 (654), 1-28, https://doi.org/10.1002/qj.776.

Deser, C., and A. Phillips, 2017: An overview of decadal-scale sea surface temperature variability in the observational record. Past Global Changes Mag., 25, 2-6, https://doi.org/10.22498/ pages.25.1.2.

d'Orgeville, M., and W. R. Peltier, 2007: On the Pacific Decadal Oscillation and the Atlantic Multidecadal Oscillation: Might they be related? Geophys. Res. Lett., 34, L23705, https:// doi.org/10.1029/2007GL031584.

Folland, C. K., J. A. Renwick, M. J. Salinger, and A. B. Mullan, 2002: Relative influences of the Interdecadal Pacific Oscillation and ENSO in the South Pacific Convergence Zone. Geophys. Res. Lett., 29, 1643, https://doi.org/10.1029/2001GL0142012. 
Frederiksen, C. S., and X. Zheng, 2004: Variability of seasonal-mean fields arising from intraseasonal variability. Part 2, application to NH winter circulations. Climate Dyn., 23, 193-206, https:// doi.org/10.1007/s00382-004-0429-6.

$\ldots, \ldots$, and S. Grainger, 2016: Simulated modes of inter-decadal predictability in sea surface temperature. Climate Dyn., 46, 2231-2245, https://doi.org/10.1007/s00382-015-2699-6.

_- X. Quan, X. Zheng, and S. Grainger, 2017: Estimating modes of inter-decadal variability and predictability in coupled climate models. ANZIAM J., 58, C82-C92, https://doi.org/ 10.21914/anziamj.v58i0.11795.

Huang, B., and Coauthors, 2017: Extended Reconstructed Sea Surface Temperature version 5 (ERSSTv5): Upgrades, validations, and intercomparisons. J. Climate, 30, 8179-8205, https://doi.org/10.1175/JCLI-D-16-0836.1.

Knight, J. R., 2009: The Atlantic Multidecadal Oscillation inferred from the forced climate response in coupled general circulation models. J. Climate, 22, 1610-1625, https://doi.org/10.1175/ 2008JCLI2628.1.

_, R. J. Allan, C. K. Folland, M. Vellinga, and M. E. Mann, 2005: A signature of persistent natural thermohaline circulation cycles in observed climate. Geophys. Res. Lett., 32, L20708, https://doi.org/10.1029/2005GL024233.

Leith, C. E., 1973: The standard error of time-average estimates of climatic means. J. Appl. Meteor., 12, 1066-1069, https:// doi.org/10.1175/1520-0450(1973)012<1066:TSEOTA $>$ 2.0.CO;2.

Li, J. P., and J. X. L. Wang, 2003: A modified zonal index and its physical sense. Geophys. Res. Lett., 30, 1632, https://doi.org/ 10.1029/2003GL017441.

Lou, J., X. Zheng, C. S. Frederiksen, H. Liu, S. Grainger, and K. Ying, 2017: Simulated decadal modes of the NH atmospheric circulation arising from intra-decadal variability, external forcing and slow-decadal climate processes. Climate Dyn., 48, 2635-2652, https://doi.org/10.1007/s00382-0163229-x

Mantua, N. J., and R. S. Hare, 2002: The Pacific Decadal Oscillation. J. Oceanogr., 58, 35-44,https://doi.org/10.1023/A: 1015820616384.

Parker, D., C. Folland, A. Scaife, J. Knight, A. Colman, P. Baines, and B. Dong, 2007: Decadal to multidecadal variability and the climate change background. J. Geophys. Res., 112, D18115, https://doi.org/10.1029/2007JD008411.
Peterson, K. B., and Pedersen, M. S., 2012: The Matrix Cookbook. Technical University of Denmark, 72 pp., http://www2.imm.dtu. dk/pubdb/pubs/3274-full.html.

Schneider, T., and I. M. Held, 2001: Discriminants of twentiethcentury changes in Earth surface temperatures. J. Climate, 14, 249-254, https://doi.org/10.1175/1520-0442(2001)014<0249: LDOTCC $>2.0 . \mathrm{CO} ; 2$.

Trenberth, K. E., 1984: Some effects of sample size and persistence on meteorological statistics. Part I: Autocorrelations. Mon. Wea. Rev., 112, 2359-2368, https://doi.org/10.1175/1520-0493(1984)112<2359: SEOFSS $>2.0 . \mathrm{CO} ; 2$.

— ability in 2005. Geophys. Res. Lett., 33, L12704, https://doi.org/ 10.1029/2006GL026894.

Watanabe, M., and Coauthors, 2014: Contribution of natural decadal variability to global warming acceleration and hiatus. Nat. Climate Change, 4, 893-897, https://doi.org/ 10.1038/nclimate2355.

Watterson, I. G., and P. H. Whetton, 2011: Distributions of decadal means of temperature and precipitation change under global warming. J. Geophys. Res., 116, D07101, https://doi.org/ 10.1029/2010JD014502.

Wilks, D. S., 2011: Statistical Methods in the Atmospheric Sciences. Academic Press, 704 pp.

Wu, C., Y. Lin, Y. Wang, N. Keenlyside, and J. Yu, 2019: An Atlantic-driven rapid circulation change in the North Pacific Ocean during the late 1990s. Sci. Rep., 9, 14411, https://doi.org/ 10.1038/s41598-019-51076-1

Yang, M.-Y, S.-I. An, J.-H. Park, and B. Wang, 2020: A global-scale multidecadal variability driven by Atlantic multidecadal oscillation. Nat. Sci. Rev., https://doi.org/10.1093/nsr/nwz216.

Ying, K., C. S. Frederiksen, X. Zheng, J. Lou, and T. Zhao, 2018: Variability and predictability of decadal mean temperature and precipitation over China in the CCSM4 last millennium simulation. Climate Dyn., 51, 2989-3008, https://doi.org/10.1007/ s00382-017-4060-8.

Zheng, X., 1996: Unbiased estimation of autocorrelations of daily meteorological variables. J. Climate, 9, 2197-2203, https:// doi.org/10.1175/1520-0442(1996)009<2197:UEOAOD>2. $0 . \mathrm{CO} ; 2$.

— arising from weather events. J. Appl. Probab., 38A, 285-299, https://doi.org/10.1239/JAP/1085496609. 